\title{
Use of Microscopy and Microanalysis in Assessing Kinetics of Degradation in 19th- Century Heritage Glasses
}

Andrew Buechele ${ }^{1}$, Lynn Brostoff ${ }^{2}$, Stephanie Zaleski ${ }^{3}$, Nikolaus Deems ${ }^{1}$, Elizabeth Montagnino ${ }^{1}$, Isabelle Muller ${ }^{1}$, Ian Pegg ${ }^{1}$, Carol Lynn Ward-Bamford ${ }^{2}$, Murray Loew ${ }^{3}$, and Xiaogang Xie ${ }^{1}$

1. The Catholic University of America, Vitreous State Laboratory, Washington, DC, USA.

2. Library of Congress, Washington, DC, USA.

3. The George Washington University, Washington, DC, USA.

The French clockmaker Claude Laurent fabricated transverse musical flutes of glass between 1806 and 1848. Many of these have, in varying degrees, undergone a process of degradation due to attack by moisture in the atmosphere and in the breaths of the flautists who have played them. A desire to preserve these precious objects led to the present study, which is part of ongoing work [1]. The intent of this research is to provide information that will help curators and owners of Laurent flutes to evaluate the relative risk to which their instruments might be subject, and to develop optimal strategies for flute preservation. Analyses show that the glasses used by Laurent for most of his flutes are high-potassium silica formulations having poor resistance to attack by moisture. A few flutes that were fabricated of high-lead crystal glass exhibit much less degradation. Since higher $\mathrm{K}_{2} \mathrm{O}$ concentration in a glass correlates with increased susceptibility to degradation [2], determination of kinetics of degradation as a function of $\mathrm{K}_{2} \mathrm{O}$ concentration provides useful information for estimating relative risk This paper presents the results of hydration studies made on model glasses within a range of compositions typical of those found in flutes fabricated by Laurent. Chips removed from the damaged foot joints of two of the flutes in the Library of Congress (LC) Dayton C. Miller collection enabled direct analysis of flute compositions, and SEM/EDS observation of actual damaged layers on the inner and outer surfaces of one of them [2]. The glass compositions of these two flutes were found to be very similar except for $\mathrm{K}_{2} \mathrm{O}$, which is about $16.4 \mathrm{wt} \%$ in one and about $21.0 \mathrm{wt} \%$ in the other. The only other component present in significant quantity is $\mathrm{CaO}$ at about $3.5 \mathrm{wt} \%$. The balance of the composition is $\mathrm{SiO}_{2}$ with about $\leq 2 \mathrm{wt} \%$ total of other minor and trace components. Model glasses were formulated and melted in the Vitreous State Laboratory (VSL) to fully simulate the compositions of the two sampled flutes, but 5 simplified model compositions were also produced by omitting the trace $(<0.1 \mathrm{wt} \%)$ components and incrementing the $\mathrm{K}_{2} \mathrm{O}$ content in $0.5 \mathrm{wt} \%$ steps from 16.5 to $20.5 \mathrm{wt} \%$. Coupons of all simulated and model glasses were subjected to artificial aging tests by two methods: a modified Vapor Hydration Test (VHT) done at VSL under $200{ }^{\circ} \mathrm{C}$ and $50 \%$ R.H. conditions with durations up to 7 days, and a second, less aggressive, test in an environmental chamber (EC) at LC set to $90{ }^{\circ} \mathrm{C}$ and $90 \% \mathrm{R}$. H. for periods of 1, 2, 3, and 7 days. Figure 1 summarizes the modification observed in the EC coupons at time intervals of 3 and 7 days for five model glasses. The strong dependence of modified layer thickness on $\mathrm{K}_{2} \mathrm{O}$ content and test duration is obvious; second-order polynomial functions of $\mathrm{K}_{2} \mathrm{O}$ content fit equally well the 7-day and 3-day data points, indicating an acceleration of the kinetics of alteration as the potassium content increases. Figure 2 compares micrographs of 7-day EC coupons. Surface micrographs show cracking patterns quite similar to those found on actual flutes. The modified layers evaluated in EDS show loss of potassium, as do layers on actual flutes [2]. Further observation at LC using Fiber Optic Reflectance Spectroscopy (FORS) also demonstrates the progressive uptake of water in test coupons with increasing test duration and coupon $\mathrm{K}_{2} \mathrm{O}$ content (Figure 3). Increase in absorbed water at the glass surface can be correlated to the height of the $\mathrm{O}-\mathrm{H}$ stretch/deformation combination peak in the shortwave infrared (SWIR) region centered at $1910 \mathrm{~nm}$. The VHT produces thicker modified layers with more structural complexity, but the observed kinetics shows consistency with EC and FORS results. 
References:

[1] I Muller et al, Goldschmidt (2017).

[2] A Buechele et al, Microsc. Microanal. 16 (Suppl 3) (2015), p. 1161.

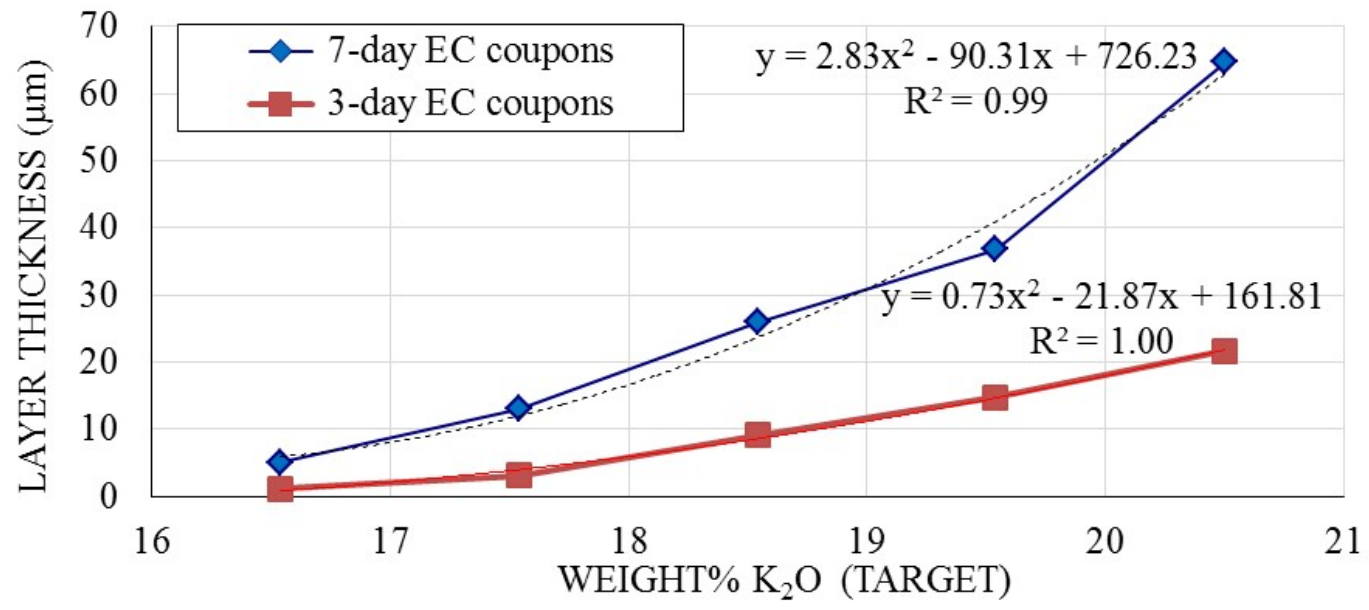

Figure 1. Depth of alteration measured in EC-treated glass coupons after 3 and 7 days, as a function of the glass potassium content. The 7-day EC coupons are shown in Figure 2 below.
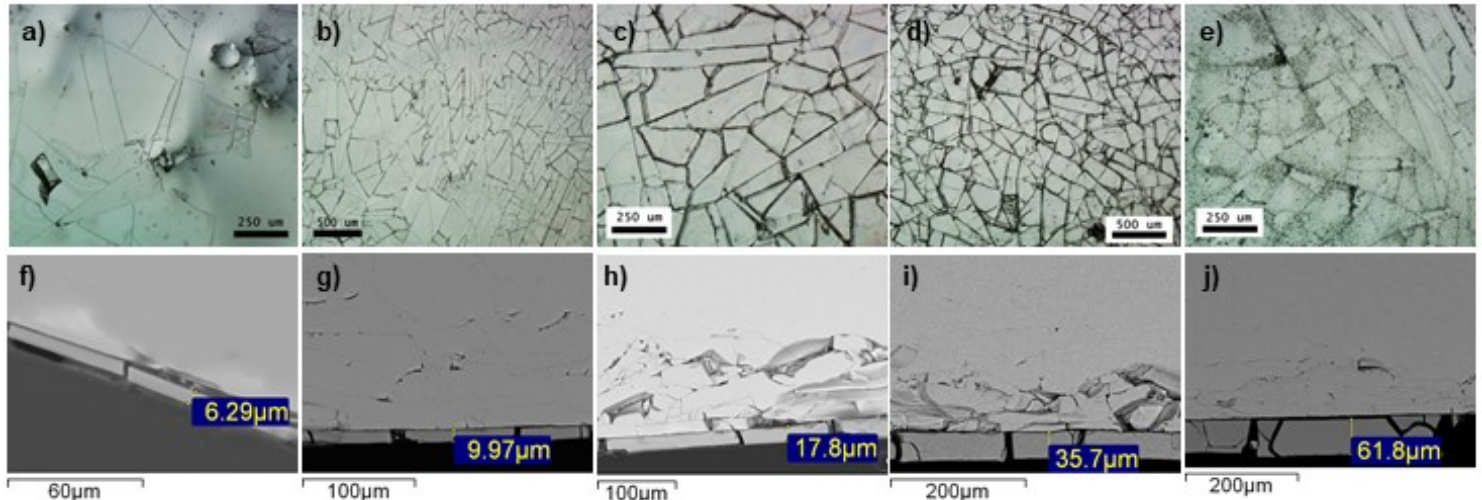

Figure 2. a-e) Visible light surface photomicrographs of EC-treated model glass $0,0.25,0.5,0.75$ and 1 after 7 days. f-j) Corresponding SEM cross sections showing thickness increase of alteration layer as $\mathrm{wt} \% \mathrm{~K}_{2} \mathrm{O}$ increases. SEM/EDS analyses of the modified layers show loss of $\mathrm{K}_{2} \mathrm{O}$.
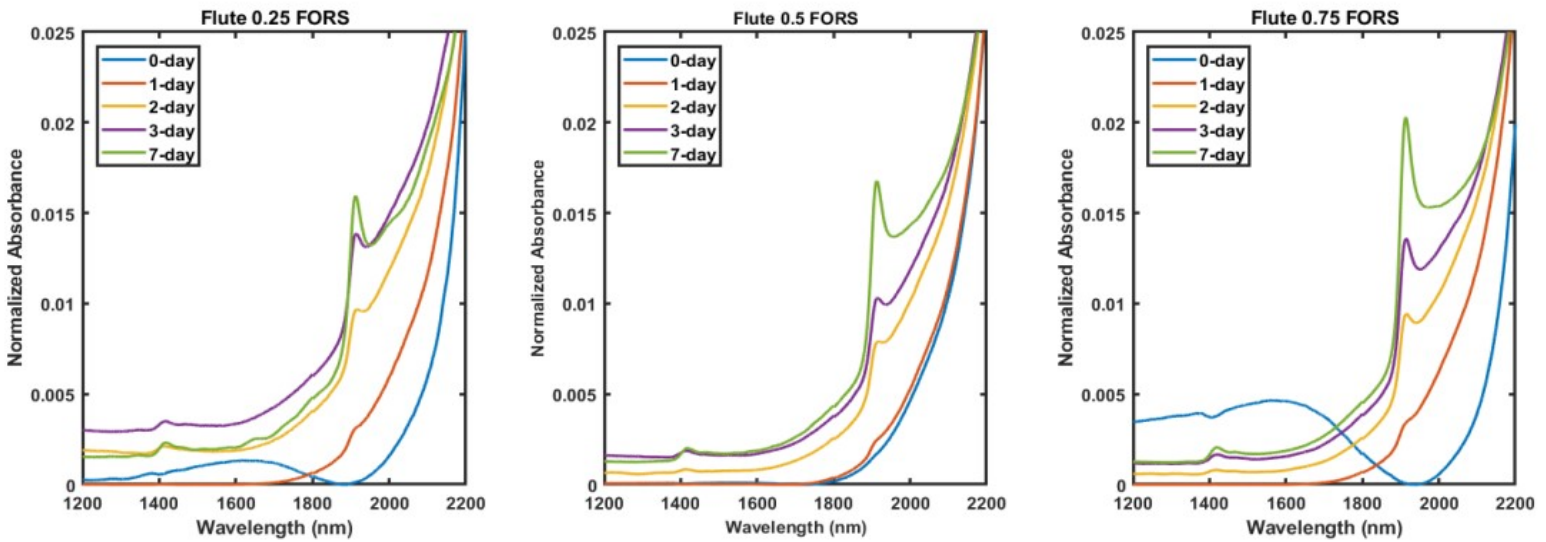

Figure 3. Fiber optic reflectance spectra taken at the surface of EC-treated glass coupons. 